\title{
Propaganda pradista: Patria, caídos y Amazonía en torno a la guerra Perú-Ecuador de 1941
}

Propagande pradiste: la patrie, les soldats tombés au combat et l'Amazonie dans la guerre Pérou-Équateur de 1941

Prado's Propaganda: The Homeland, The Fallen and Amazonia, in the Peru-

Ecuador War of 1941

\section{François Bignon}

\section{OpenEdition}

\section{Journals}

Edición electrónica

URL: http://journals.openedition.org/bifea/9646

DOI: $10.4000 /$ bifea.9646

ISSN: 2076-5827

\section{Editor}

Institut Français d'Études Andines

\section{Edición impresa}

Fecha de publicación: 1 agosto 2018

Paginación: 117-140

ISSN: 0303-7495

\section{Referencia electrónica}

François Bignon, «Propaganda pradista: Patria, caídos y Amazonía en torno a la guerra Perú-Ecuador de 1941 », Bulletin de l'Institut français d'études andines [En línea], 47 (2) | 2018, Publicado el 08 agosto 2018, consultado el 04 noviembre 2020. URL : http://journals.openedition.org/bifea/9646 ; DOI : https://doi.org/10.4000/bifea.9646

\section{(c) $(1) \odot$}

Les contenus du Bulletin de l'Institut français d'études andines sont mis à disposition selon les termes de la licence Creative Commons Attribution - Pas d'Utilisation Commerciale - Pas de Modification 4.0 International. 


\title{
Propaganda pradista: Patria, caídos y Amazonía en torno a la guerra Perú-Ecuador de 1941
}

\author{
François Bignon*
}

\begin{abstract}
Resumen
La guerra de corta duración entre Perú y Ecuador en 1941 involucró rápidamente a las muchedumbres peruanas en pro de la defensa del territorio y en respaldo al Gobierno de Manuel Prado. Este supo sacar provecho de este entusiasmo organizando o inspirando una propaganda activa a través de canales variados como las marchas patrióticas, el cine, una exposición cultural y un monumento conmemorativo. El contenido de esta propaganda, inicialmente orientada hacia el respaldo popular al Presidente, la búsqueda de la paz y los caídos por la Patria, se enfoca después de la guerra en la integración definitiva de la Amazonía al territorio peruano. A pesar de la derrota electoral de 1945 que muestra las dificultades e incluso las críticas al accionar del Gobierno, la variedad de soportes y la coherencia del mensaje, equiparables con los esfuerzos de las grandes potencias de aquel entonces, invitan a repensar la modernidad política de Perú de los años 1940.
\end{abstract}

Palabras clave: propaganda, conflicto Perú-Ecuador, Amazonía, cine, patriotismo, identidad nacional

\section{Propagande pradiste : la patrie, les soldats tombés au combat et l'Amazonie dans la guerre Pérou-Équateur de 1941}

\section{Résumé}

La guerre courte qui opposa le Pérou à l'Équateur en 1941 mobilisa rapidement les foules péruviennes autour de la défense du territoire et de l'appui au gouvernement de Manuel Prado. Ce dernier sut tirer parti de cet enthousiasme en organisant ou en inspirant une propagande active à travers divers canaux tels que des manifestations patriotiques, le cinéma, l'exposition culturelle et un monument

\footnotetext{
*Université de Rennes, Arènes UMR 6051. E-mail: bignonf@hotmail.fr
} 
commémoratif. Le contenu de cette propagande, qui porte d'abord orienté sur le soutien populaire au Président, la recherche de la paix, et les soldats tombés au combat, se concentre après la guerre sur l'intégration définitive de l'Amazonie au territoire péruvien. Malgré la défaite électorale de 1945 qui montre un essoufflement, voire des critiques à l'action gouvernementale, la variété des supports et la cohérence du message, comparables aux efforts des grandes puissances d'alors, invitent à repenser la modernité politique du Pérou dans les années 1940.

Mots-clés : propagande, guerre Pérou-Équateur, Amazonie, cinéma, patriotisme, identité nationale

\title{
Prado's Propaganda: The Homeland, The Fallen and Amazonia, in the Peru-Ecuador War of 1941
}

\begin{abstract}
The short war that took place between Peru and Ecuador in 1941 mobilized Peruvian crowds for the defense of the territory and the support of Manuel Prado's government. Its knew how to capitalize on this enthusiasm, by organizing or inspiring an active propaganda campaign through various channels such as patriotic demonstrations, cinema, cultural exhibition, and a memorial. The content of this propaganda at first was oriented to building popular support for the President, the peace process and the fallen soldiers in the war. After the war, it focused on the definitive integration of Amazonia to the Peruvian Territory. In spite of the electoral defeat in 1945 that showed the weakness and criticisms of the government actions, the variety of means and coherence of the message, comparable to the other great powers at that time, invite a rethinking of political Modernity in Peru during the early 1940s.
\end{abstract}

Key words: Propaganda, Peru-Ecuador conflict, Amazonia, Cinema, Patriotism, National Identity

En julio y agosto de 1941, una corta e intensa guerra en la frontera entre Perú y Ecuador tuvo como resultado la victoria militar peruana y la firma del llamado Protocolo de Río de Janeiro que aseguró a Perú el dominio de territorios que tenían una delimitación poco clara desde la Independencia. El antiguo pleito se había avivado de nuevo con ocasión del conflicto de Leticia (1932-1933) entre Perú y Colombia, cuando los ecuatorianos intentaron integrar las negociaciones, lo que reactivó el juego diplomático entre Quito y Lima para la posesión de territorios fronterizos ubicados entre Tumbes, en la Costa, y el río Napo, en la Amazonía. Después de varios años de tensión diplomática, los pequeños choques fronterizos se multiplicaron entre los años 1940 y 1941 hasta desencadenar una guerra, en un contexto de crisis mundial (Bignon, 2015).

La historia tradicional de estos acontecimientos narra en general las operaciones militares en el campo de batalla — principalmente en la Costa y en segundo lugar en la Selva - y el proceso diplomático que llevó a su solución mediante la firma del Protocolo de Río1 ${ }^{1}$. Estos acercamientos requieren ser estudiados de nuevo con una mirada al conflicto que tome en cuenta las dimensiones políticas,

1 La mejor síntesis del lado peruano sobre los acontecimientos militares es Zanabria Zamudio (1996). Del lado ecuatoriano la suma más reciente e imponente es Gándara Enríquez (2000). Sobre el 
económicas, sociales y hasta artísticas de la guerra, a fin de medir su impacto en la sociedad peruana de aquella época. Al respecto, el enfoque de la propaganda gubernamental permite abarcar todas estas dimensiones y su relación con la opinión pública peruana.

La propaganda², que podríamos definir como «la expresión de una opinión o una acción por individuos o grupos, deliberadamente orientada a influir opiniones o acciones de otros individuos o grupos para unos fines predeterminados y por medio de manipulaciones psicológicas» (Violet Edwards, citada en Pizarroso Quintero, 1999: 147), fue usada por el Gobierno de Manuel Prado (1939-1945) de varias formas con dos propósitos.

El primero era fortalecer la posición internacional de la cancillería peruana frente a los ecuatorianos y a los países que sirvieron de mediadores (Estados Unidos, Argentina, Brasil y, posteriormente, Chile). Perú temía un arreglo diplomático que le otorgara menos territorio del que controlaba efectivamente, por lo que necesitaba demostrar a los otros países que su población respaldaba sus máximas pretensiones.

El segundo objetivo de la propaganda pradista atañía a la situación propiamente peruana: se trataba de mantener apaciguados a varios grupos que podían tener la tentación de realizar un golpe de Estado, en una atmósfera política de «casi guerra civil» desde el principio de los años 1930 (Lossio \& Candela, 2015; Denegri Luna, 1996: 298).

Finalmente hay que subrayar también que Prado tenía razones personales para mostrarse más patriótico que cualquier otro líder. La familia Prado había heredado un pasado familiar turbio desde que el padre, Mariano Ignacio Prado, se marchó repentinamente del país durante la Guerra del Pacífico, alimentando desde entonces las acusaciones de traición a la Patria. El origen de la fortuna de la familia era entonces sospechoso y el propio hermano de Manuel, Jorge, había sufrido ataques de adversarios siendo candidato presidencial en 1936, alimentando un «complejo reparativo» (Portocarrero, 1995: 31).

Al respecto de la propaganda, Pizarroso Quintero (1999) advierte que lo más fácil es estudiar los canales, el contenido y las técnicas, ya que son las partes visibles de la propaganda, y es lo que se propone principalmente en este trabajo. En cuanto a la organización emisora, se sabe que existía una Dirección de Propaganda e Información en el Ministerio de Gobierno y Policía, pero no hemos podido ubicar sus archivos ${ }^{3}$. También existía una Oficina de Informaciones cuyas publicaciones

contexto diplomático, véase Yepes (1998). Para su relación con el contexto diplomático mundial, véase Bignon (2015). Uno de los únicos acercamientos sociopolíticos es Ibarra (1999).

2 Sobre esta noción de propaganda considerada de manera histórica, véase Pizarro Quintero (1990; 1999). El tema ha sido también delimitado en francés por Almeida (2013) y Ellul (1967). Más recientemente, las cuestiones de propaganda en contexto de guerra se han referido naturalmente a la Primera Guerra Mundial con ocasión de su centenario (Facon, 2013; Pastor, 2013).

3 Todos los archivos del Ministerio de Gobierno y de la Prefectura de Lima de 1941 ubicados en el Archivo General de la Nación (AGN-Perú), sección republicana, han sido consultados para tal propósito, sin dar muchos resultados. 
hemos tomadas en cuenta. Adicionalmente, el Ministerio de Relaciones Exteriores creó, en setiembre de 1941, una «Agencia Amazonas» para «realizar los envíos de propaganda con la cuestión limítrofe, dentro y fuera del territorio nacional»4 En cuanto al tema de las repercusiones de la propaganda, se aborda aquí las reacciones de la opinión pública frente al mensaje transmitido, cómo lo interpreta y se forja una opinión a partir de este, para que finalmente pueda influir en la toma de decisiones. Aquí entramos en el campo del estudio de la opinión pública en situación internacional, el cual ha sido profundamente renovado desde los años 1990 (Frank, 2012: 345-370).

Varios factores incitan a estudiar esta opinión pública en el Perú de los años 1930. El desarrollo de medios de comunicación masiva, como la prensa, la radio y el cine5; la aparición de partidos de masa, como la Unión Revolucionaria y el APRA; y la «liberalización limitada» del juego electoral influyeron en que durante los años 1930, tanto en la política nacional como internacional, la opinión pública pesara cada vez más (López \& Barrenechea, 2005). El antecedente histórico de Leticia así lo demuestra. Cuando en 1932 un grupo de militares y civiles de Loreto tomaron el puerto colombiano de Leticia, al presidente Sánchez Cerro no le quedó otro remedio que apoyarlo, aunque no quisiera hacerlo en un principio. En este caso, la opinión pública prevaleció sobre la diplomacia (Camacho Arango, 2016).

Esta opinión se expresaba y era difundida a través de la prensa, medio tradicional, así como a través de la radio y del cine, o mediante numerosas manifestaciones populares, cívicas y artísticas. La propaganda es polimórfica. La diversidad de sus canales, que es su particularidad, constituye precisamente la dificultad de su estudio, porque implica manejar disciplinas generalmente separadas como la historia política, el arte, la diplomacia, los medios de comunicación, etc. Por esta razón, si bien nos interrogaremos en este trabajo acerca de la evolución de los canales de la propaganda pradista, no hemos llevado a cabo un estudio exhaustivo de lo que se ha dicho, escrito y grabado sobre el conflicto entre 1941 y 1945. En cambio, se han escogido algunos momentos y medios característicos del discurso directo e indirecto del Gobierno Prado, visibles en los archivos, en la prensa y en el espacio público6.

Este trabajo sigue estas pautas para el análisis de la trama cronológica de 1941 a 1945. Un vistazo a estos eventos muestra un entusiasmo patriótico aparentemente sin fin, de cara a la política gubernamental con respecto a Ecuador antes, durante

4 AGN-Perú, sección republicana, MI 416, 16 de setiembre de 1941.

5 Después del lanzamiento de la primera emisora en Lima en 1924, la década de los años 1930 es la del despegue de la radio. En cuanto al cine sonoro, la primera proyección ocurrió en 1929 y en los años siguientes se importaron películas extranjeras y se grabaron otras peruanas. Véase Contreras \& Cueto, eds. (2015: 284-291).

6 En el caso de la prensa, siempre se ha consultado cuando se refería a un evento destacado conocido por otro medio, y en particular por los informes del embajador de Francia en Lima que remitía con regularidad síntesis de las opiniones expresadas en la prensa de la capital. Estos informes son conservados en los archivos diplomáticos franceses (Archives du Ministère des Affaires Étrangères, AMAE-La Courneuve). 
e inmediatamente después de la guerra. Analizamos así en la primera parte del estudio las distintas presiones sobre Prado, las que llevaron al empleo de diferentes canales de demostración de apoyo popular para respaldar el uso de una acción armada para defender el territorio patrio. El artículo muestra después que la propaganda del Gobierno de Prado fue una respuesta a las evoluciones de la opinión pública y que los cambios en el contenido, precisamente el énfasis en la Amazonía que estudiamos en la segunda parte, están directamente ligados a las ambiguas reacciones peruanas a la solución diplomática de la guerra.

\section{LA BORRACHERA PATRIÓTICA Y SUS LÍMITES (1941-1942)}

\section{1. La familia Prado bajo la presión popular}

Después de que las relaciones entre Ecuador y Perú se tornaran tensas a lo largo de los años 1940 y 1941 a raíz de pequeños choques fronterizos, la primera gran reacción del pueblo peruano a esta situación se produjo en mayo de 1941, unos días después de que Estados Unidos, Brasil y Argentina propusieron constituirse como mediadores. Esta gestión multilateral del pleito, deseada por Quito, era contraria a la estrategia diplomática de Lima por lo que la cancillería del Rímac reaccionó fuertemente a través de notas diplomáticas y de la prensa7 ${ }^{2}$ En este contexto estallaron tres días de manifestaciones patrióticas, entre el 13 y el 16 de mayo de 1941, que animaron las calles de Lima y de las grandes ciudades del país. Primero, delegaciones del senado, de la cámara de diputados y de la municipalidad de Lima, visitaron al presidente Manuel Prado en Palacio para asegurarle de su apoyo frente a las presiones internacionales. En esta ocasión, el Presidente pronunció muchos discursos improvisados; en uno de ellos afirmaba específicamente el carácter «sagrado de nuestro territorio» y en particular de las tres provincias de Tumbes, Jaén y Maynas, de las que no se cedería «ni una pulgada». En los días siguientes, todo Lima y el país vivieron en un estado de fervor patriótico, y delegaciones de estudiantes, profesores, fiscales, miembros de la Iglesia Católica, bomberos, maestros, que apoyaban la actitud vindicativa del Presidente en el litigio limítrofe, lo visitaron. En el interior, las municipalidades, los prefectos y los gremios organizaron manifestaciones en todas las grandes ciudades vitoreando al Presidente, al ejército y a la integridad nacional. Asistieron a ellas alrededor de 40000 personas en Arequipa y Cusco, 20000 en Iquitos, 15000 en Chiclayo, y miles en Piura, Pucallpa, Tumbes, Chincha, etc. (Oficina de Informaciones del Perú, 1941). Las cifras oficiales están seguramente sobredimensionadas, pero las fotos muestran efectivamente grandes concentraciones (fig. 1). En sus discursos, Prado señaló que estas manifestaciones representaban no solo un apoyo al Gobierno, sino también un llamado a seguir siendo inflexible en las negociaciones internacionales. De hecho, según el comentario del embajador francés,

7 Perú no estaba a favor de la interferencia de otras potencias en aquel momento, sobre todo de Estados Unidos, y prefería negociar directamente con Ecuador, muy al contrario de su posición anterior durante el arbitraje fallido del Rey de España (Martínez Riaza, 1998a). 
afirmar el carácter sagrado del suelo peruano significaba un paso adelante hacia el conflicto con Ecuador, cerrando las posibilidades de negociación diplomática8. En esta atmósfera de borrachera patriótica, un decreto supremo estableció que la Bandera nacional ya no saludaría al Presidente, sino que sería de aquí en adelante el Presidente que se inclinaría frente a ella9.

La presión popular sobre la persona misma de Prado era entonces evidente. Además de la mácula familiar ya mencionada, siempre existía la posibilidad de un derrocamiento militar contra un poder civil recientemente instaurado; más aún cuando muchos oficiales conformaban las marchas patrióticas según fuentes francesas10, lo cual se

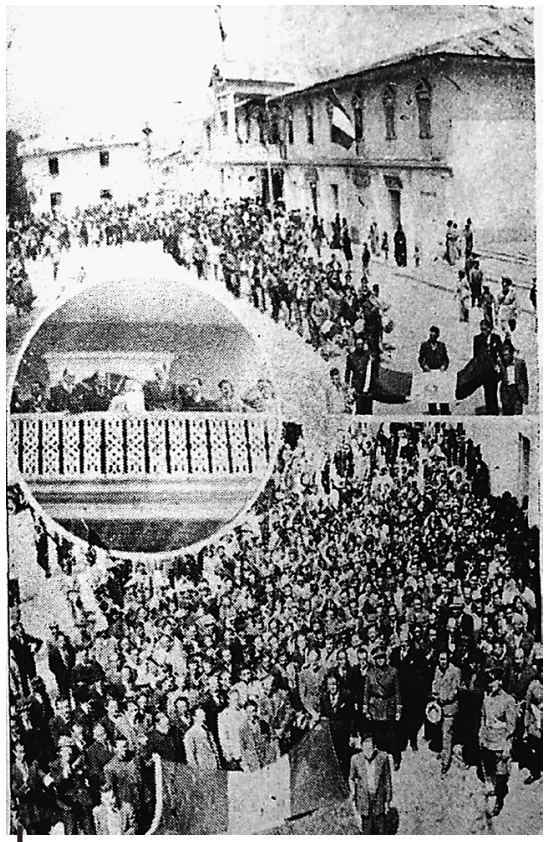

Figura 1 - Marcha patriótica de respaldo al presidente Prado en Jauja, mayo de 1941 (Oficina de Informaciones del Perú, 1941)

(C) Oficina de Informaciones del Perú puede apreciar en la figura 2. Parece incluso que los altos mandos de las Fuerzas Armadas presionaron al Presidente para lograr un aumento del presupuesto de Defensa y luego desencadenar el conflicto armado (Masterson, 2001: 103-105)11.

A pesar de esta presión, se puede pensar que Manuel Prado o algunas autoridades sacaron partido de, e incluso fomentaron, estas manifestaciones. Las marchas solían ser organizadas por los prefectos bajo la autoridad del Ministerio de Gobierno ${ }^{12}$. Las de mayo de 1941, estructuradas en gremios y contando con autoridades civiles y militares, convenían al Gobierno tanto en el ámbito interno, porque tranquilizaban a los altos mandos militares, como en el teatro exterior, porque fortalecían su posición diplomática frente a Ecuador. Este país experimentaba, por su parte, campañas de prensa igualmente patrióticas pero que atacaban a menudo la labor de su propio Gobierno ${ }^{13}$. En última instancia se trataba de neutralizar el trabajo de los países mediadores que hubiera conducido a un acuerdo diplomático desfavorable a la posesión de facto de los peruanos.

El aprovechamiento de este brote de patriotismo por parte de Prado para restablecer el honor familiar se

8 Tal como lo afirma el representante de Vichy en una carta: Raymond Lavondès, ministro de Francia en el Perú, al almirante Darlan, ministro de Relaciones Exteriores de Francia, 14 de mayo de 1941, AMAE-La Courneuve.

9 AGN-Perú, Sección republicana, MI 415.

10 Raymond Lavondès, ministro de Francia en el Perú, al almirante Darlan, ministro de Relaciones Exteriores de Francia, 14 de mayo de 1941, AMAE-La Courneuve.

11 El mes siguiente de las marchas, el general Ureta habría remitido un ultimátum al presidente Prado para atacar Ecuador.

12 A pesar de esta costumbre, no se han encontrado indicios de ello en el archivo de la Prefectura de Lima de ese año, ubicado en el Archivo General de la Nación.

13 El canciller ecuatoriano de esos años alude varias veces en una obra que se hizo famosa sobre el litigio a las críticas por parte de la prensa que enfrentaba su Gobierno (Tobar Donoso, 1982). 


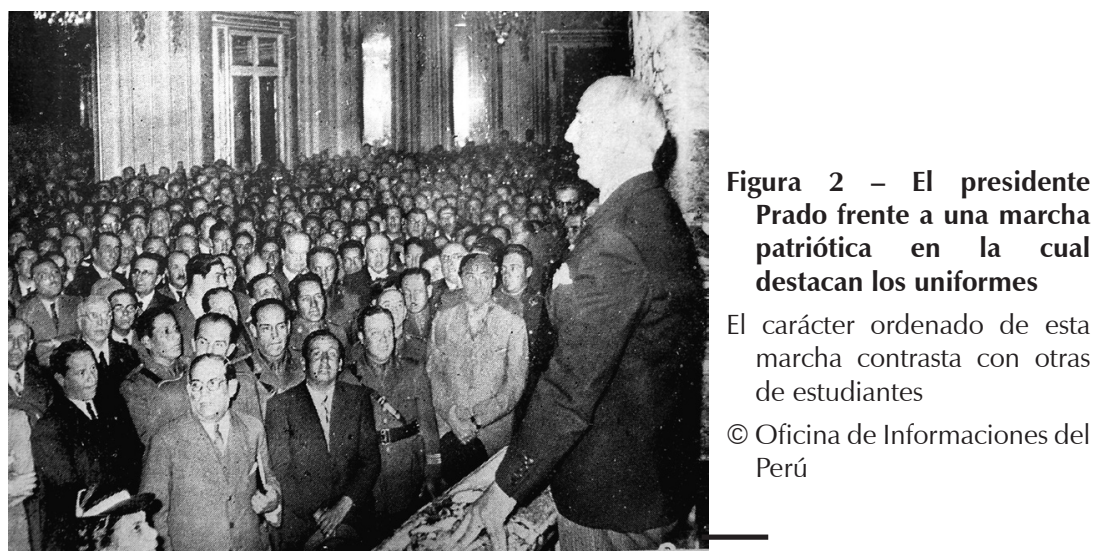

observa también en la estrategia comunicacional alrededor de su esposa y de su hija. Durante los combates, Enriqueta Garland Prado viajó al frente, acompañada de su hija Rosa, para servir como enfermera. En realidad, como lo muestra la cinta Alerta en la Frontera, distribuía víveres a los soldados frente a las cámaras complacientes, en una estrategia de comunicación política bien pensada. De regreso a Lima, fue aclamada en las calles y la Cámara de Diputados resolvió colgar su retrato y el de su hija en el Palacio de Gobierno, «por su abnegada actuación en la campaña del Norte»14.

\section{2. La manifestación en el Estadio Nacional del Perú del 16 de agosto de 1941}

Los hechos bélicos que siguieron las manifestaciones patrióticas de mayo son conocidos a grandes rasgos. Las escaramuzas se convirtieron en batalla de gran escala a finales del mes de julio, principalmente en la costa donde la principal operación quedó en la historia con el nombre de «batalla de Zarumilla». El alto al fuego fue firmado y los ejércitos separados por una zona desmilitarizada, pero combates de menor importancia siguieron dándose en la zona amazónica mientras las Fuerzas Armadas de Perú ocupaban la provincia ecuatoriana de El Oro a la espera del arreglo diplomático que tuvo lugar en enero de 1942 en Río de Janeiro.

En Lima, la pronta victoria desató una de las manifestaciones consideradas de mayor asistencia en la historia republicana de Perú, con más de 100000 personas presentes en el Estadio Nacional del Perú. El representante diplomático de Francia en Lima, Raymond Lavondès, describió así el desarrollo de la ceremonia:

[El estadio] había sido cambiado para tal circunstancia: tribuna oficial decorada con los colores nacionales, torres luminosas (porque ocurría a

14 Secretaría de la Cámara de Diputados al Señor Ministro de Estado en el Despacho de Gobierno y Policía, 14 de agosto de 1941 (AGN-Perú, sección republicana, MI 418, 1941). 


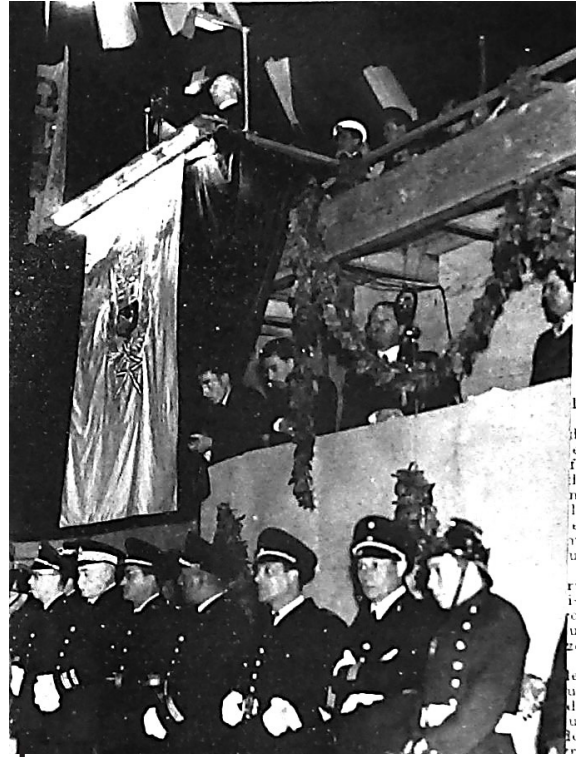

Figura 3 - El presidente Prado en la manifestación del Estadio Nacional

El decorado muestra claramente las intenciones triunfalistas de la manifestación.

(C) Turismo: Revista de viajes, artes y actualidad agosto de 1941

las 7 de la noche), plataforma elevada en medio del estadio, en la cual se había colocado una ánfora donde debía quemarse la llama del recuerdo, trofeos constituidos por cañones, fusiles, ametralladoras ecuatorianas, carteles inmensos con los nombres de las tres provincias peruanas, Tumbes, Jaén y Maynas, reivindicadas por Ecuador, etc. Al llegar el Presidente de la república recibió un sinfín de aclamaciones por parte de la muchedumbre. Rodeado de los miembros del Gobierno, alumbró la llama simbólica; el arzobispo de Lima rezó por los caídos, y se observó un minuto de silencio ${ }^{15}$.

No cabe duda de que esta manifestación de respaldo a Prado y a su política bélica era todo menos espontánea. La concepción, fabricación e instalación del decorado requirieron con seguridad cierto tiempo (fig. 3), y la simbología elegida con precisión, para aparentar un respaldo popular, podía remitir a los triunfos romanos con la exhibición de las armas de los vencidos o, más recientemente, a los desfiles de Núremberg (Bytwerk, 2004). En cuanto a la asistencia numerosa, efectivamente masiva, el hecho de que las autoridades prohibieran la apertura de todo local público en Lima esa noche fue seguramente un factor coayuvante 16. Otra vez encontramos una manipulación, o por lo menos una puesta en escena del respaldo popular al Gobierno. Hay que subrayar que, además de presentar al Presidente como un héroe, la ceremonia introducía la figura de los soldados caídos que sería reiteradamente usada en la propaganda posterior ${ }^{17}$.

Al finalizar esta reunión patriótica, el embajador francés anotaba que los limeños empezaban a «encontrar exagerado» este esfuerzo de propaganda. La percepción de que el Gobierno había ido demasiado lejos en festejar la victoria se encuentra también en la pluma de los colaboradores del Presidente (Denegri Luna, 1996: 297-299). Los límites de esta estrategia comunicacional aparecerían aún más claramente con el uso de otro medio nuevo: el cine.

15 Raymond Lavondès, ministro de Francia en el Perú, al almirante Darlan, ministro de Relaciones Exteriores de Francia, 17 de agosto de 1941, AMAE-La Courneuve. Las citas siguientes son de la misma carta (traducción del autor).

16 Raymond Lavondès, ministro de Francia en Perú, al almirante Darlan, ministro de Relaciones Exteriores de Francia, 17 de agosto de 1941, AMAE-La Courneuve.

17 Las cifras oficiales de la época evocan poco más de 80 caídos del lado peruano. Las bajas fueron seguramente mucho mayores del lado ecuatoriano, pero no existen cifras oficiales. 


\section{3. La película Alerta en la frontera ${ }^{18}$ y los límites de la propaganda bélica}

Es probable que el Gobierno no estuviera detrás de esta propuesta cinematográfica, sino que un grupo de técnicos viera en la guerra una oportunidad para grabar un material original que fuera después recuperado por el Gobierno y el Estado Mayor. Esta película de 1941, que se encontró en el archivo del Ejército en 2014, fue dirigida por Kurt Hermann, cuya compañía, Herman Films Production, se había establecido en Lima este mismo año, con tecnología y técnicos «traídos directamente de New York y Hollywood», con el fin de conseguir «la instalación de una Productora Nacional de Películas, que responda en su capacidad técnica al nivel de las mejores películas norteamericanas» 19 . Alerta en la frontera es el primer largometraje de la ambiciosa productora. La cinta de más de una hora, destinada a mostrarse en los cines de la capital peruana, mezclaba imágenes documentales grabadas en Lima y en el resto del país con escenas bélicas recreadas directamente en el frente de batalla con la colaboración de las Fuerzas Armadas.

El argumento de la cinta sigue las pautas de la guerra. Empieza con imágenes documentales de un Perú en paz: jóvenes divirtiéndose patinando en traje de baño, corridas, peruanas trabajando. El comentario subraya que Perú es «pacífico (...) conviviendo con sus vecinos (...) dentro del derecho internacional». La acción se desplaza hacia los puestos fronterizos de la costa norte donde los militares vigilan. De pronto se presencia el anuncio de un ataque ecuatoriano que llega al general Eloy Ureta y a su más cercano colaborador el teniente coronel Miguel Monteza Tafur, jefes del Agrupamiento del Norte. Estos oficiales, obviamente, tuvieron que actuar estas escenas para la narrativa después de que la guerra empezara. En ellas se muestra la organización de la respuesta y el despliegue de todas las fuerzas peruanas de aire, mar y tierra, con sus tanques, aviones y buques de guerra. Los primeros éxitos son para los peruanos que capturaron pertrechos de guerra ecuatorianos, prueba de que el vecino del norte había preparado el ataque. Fallecen las primeras víctimas, y aunque la película muestra muy pocos caídos, insiste en la labor de las enfermeras y de los médicos. Todos los sectores de la población parecen de esta manera respaldar a las Fuerzas Armadas. La cámara registra a continuación las localidades ecuatorianos abandonados, ya que su población ha huido de sus propios soldados. Al contrario los soldados peruanos «con la generosidad y la honradez que los caracterizan», respetan a la propiedad ajena «como la suya propia». De hecho, la ocupación de la provincia de El Oro que sigue, y que duró varios meses, es presentada como respetuosa, «resguardando las plantaciones y sembríos abandonados, (...) Se restablece el comercio (...) el tráfico se normaliza». Las caras sonrientes de estos ecuatorianos,

${ }^{18}$ Documental de Kurt Hermann (1941); Producción: Federico Uranga; Fotografía: Manuel Trullen; Sonido: Bertalan Petrick; Narración: Ricardo Villarán; Locutor: Gustavo Montoya; Ayudantes: Pedro Valdivieso, Cesar Chugo y Jorge Torrico; Música: Marcha Zarumilla y Cabalgata de las Valkirias (Wagner).

${ }_{19}$ AGN-Perú, Sección Republicana, MI 144, 1941. 
y las menos sonrientes pero sin huellas de maltrato de los soldados ecuatorianos capturados («Aquí no hay enemigo») respaldan el punto.

Pasadas las operaciones militares, la película aborda la visita al frente de Enriqueta Prado y de su hija, quienes regresan a Lima en medio de una multitud. La cinta muestra a continuación el homenaje de la nación a Manuel Prado en el Estadio Nacional del Perú, y el regreso posterior y triunfal del general Ureta a Lima, aclamado por el Congreso. La película se cierra sobre las palabras fuertes del Presidente, pronunciadas durante las grandes marchas patrióticas de mayo, «ni ahora ni nunca cederá Perú ni una sola pulgada de su territorio».

A diferencia de la cinta Yo perdí mi corazón en Lima (Alberto Santana, 1933)20 que se estrenó durante el anterior conflicto internacional de Perú con Colombia, Alerta en la Frontera es ante todo un documental de guerra y de patriotismo. Salvo en las escenas de batallas (fig. 4), la película se enfocaba además en algunos personajes clave del conflicto armado: el presidente Prado, sus discursos patrióticos, su esposa y su hija en el frente (fig. 5), y la figura del general Eloy G. Ureta, el cerebro detrás de las operaciones militares en el norte y el gran héroe de esta guerra, quien se ganó el apodo de «vencedor de Zarumilla». Llama la atención que, en contraste con películas más antiguas y a pesar de que los territorios selváticos fueron un ámbito importante de esta guerra, casi no fueron mencionados en la cinta21.

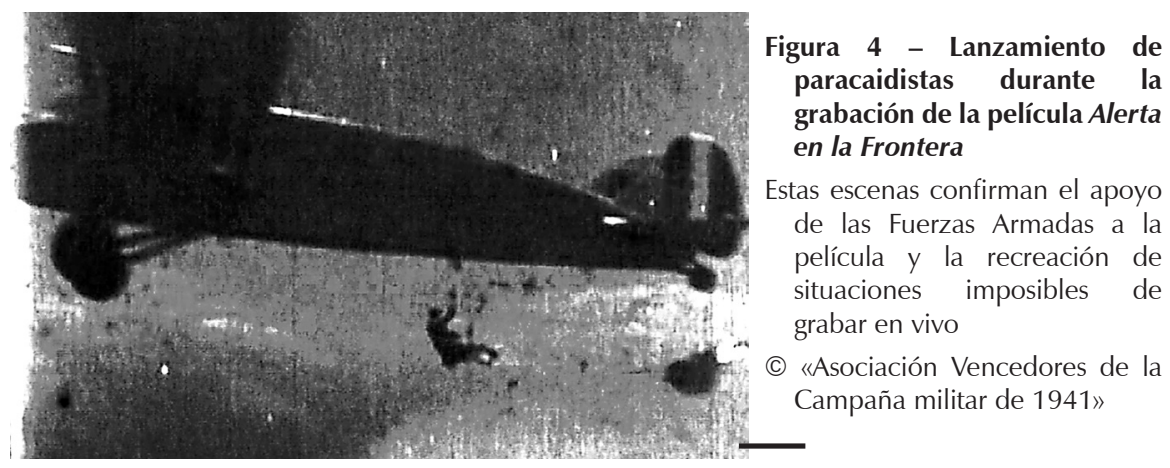

20 Esta era una película ambientada en la actualidad bélica pero que desarrollaba principalmente el «drama de la femineidad lacerada y pasiva» (Bedoya, 1997: 81).

21 Las cintas sobre la Amazonía habían sido producidas por intereses ligados a los tradicionales grupos de poder de esta zona (casas de comercio, órdenes religiosas, etc.), cuando al contrario Alerta en la Frontera es una película privada pero con carácter casi oficial debido a su discurso. Las principales filmaciones sobre la Amazonía anteriores a 1941 fueron El Oriente Peruano (1926), producida por el cauchero César Arana para atraer inversiones y limpiar su nombre de los llamados crímenes del Putumayo; La Conquista de la Selva (1929), documental producido por los Franciscanos y apoyado por Augusto Leguía; Sangre de Selva (1937), persecución en la selva del Perené, y Bajo el Sol de Loreto (1932), serie de corto metrajes del fotógrafo Antonio Wong Rengifo sobre la región, comportando elementos sobre el conflicto de Leticia (Bedoya, 1997). 
A pesar de un marcado discurso pacifista, los hechos presentados en la película bombardeos, ocupación militar- tenían un tono claramente triunfalista, enfatizado por la música de la Cabalgata de las valkirias de Wagner, que resaltaba la victoria militar sobre el vecino del norte, justificando la guerra como medio para alcanzar la paz. En razón de que este tono podía perjudicar la acción diplomática de Perú, la película nunca llegó a verse en los cines limeños (Bedoya, 2014)22.

La censura de último minuto ilustra los límites de la propaganda bélica en torno al conflicto. Mostrándose demasiado triunfador, y ocupando todavía la provincia ecuatoriana de El Oro, Perú podía ser visto como el agresor, y por lo tanto incumplir con las normas jurídicas internacionales ${ }^{23}$. A esta altura del conflicto, el Gobierno ya no necesitaba el respaldo masivo de su

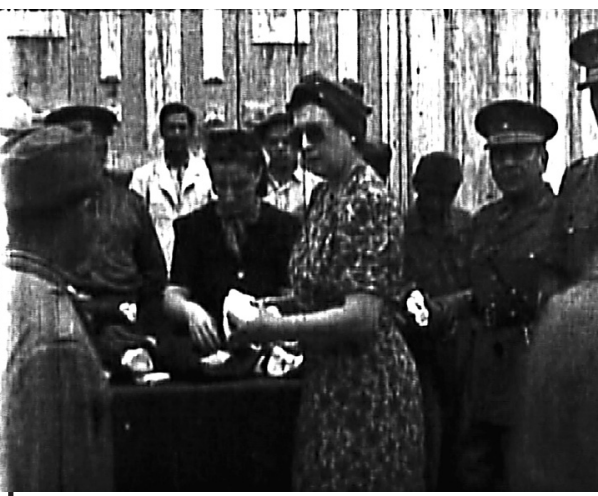

Figura 5 - La esposa del Presidente, Enriqueta Prado Garland, visita la frontera y distribuye paquetes a los soldados frente a las cámaras, en un espectáculo propagandístico bien controlado

En la escena siguiente, se quita los lentes para que se le vea la cara. La esposa y la hija del Presidente desempeñaron un papel importante en la propaganda del Gobierno

(C) «Asociación Vencedores de la Campaña militar de 1941» pueblo sino la respetabilidad internacional.

Así se puede interpretar la prohibición de la exhibición de la película como un punto de quiebre en la estrategia comunicacional de las autoridades peruanas. A partir de finales de 1941 y más aún con el arreglo definitivo del Protocolo de Río de Janeiro, los esfuerzos se enfocarían en la justificación de los hechos pasados y la consolidación de territorios cuyo dominio peruano ya no se discutiría.

\section{DESPUÉS DE LA GUERRA (1942-1945): LA INTEGRACIÓN DE LA SELVA EN EL RELATO NACIONAL}

El llamado Protocolo de Río de enero de 1942 no solo permitió a Perú controlar una porción de territorio amazónico nunca antes alcanzado, sino también poner fin a una antigua controversia, y abría paso a la estabilidad de los límites territoriales entre los dos países²4.

22 Alerta en la Frontera siguió así la misma suerte que Páginas Heroicas, otra cinta que en 1926 había sido censurada para no lastimar las relaciones de Perú con su vecino chileno (Bedoya, 1995: 49-51).

23 Otra razón podría ser el papel demasiado importante otorgado al general Ureta que hubiese podido, con su popularidad, encabezar un golpe de Estado contra el Gobierno de Manuel Prado.

24 El cálculo del tamaño del territorio que cambia de manos en ese entonces varía de acuerdo a los textos tomados en cuenta. Para el canciller ecuatoriano Julio Tobar Donoso, el Perú ganó $13500 \mathrm{~km}^{2}$ de selva amazónica adicionales a los que le reconocía el statu quo de 1936 (Tobar Donoso, 1982: 462). Para una publicación oficial peruana de 1942, la línea pactada en 1942 es «superior de 30000 kilómetros cuadrados a la línea de posesión de Perú en cualquier periodo de [su] historia» (El protocolo de Río ante la historia, 1942). 
Si bien la consternación de la población ecuatoriana era generalizada, en Perú no toda la opinión pública fue entusiasta con respecto al tratado, y sería un error dar por sentado como lo hacía un documento oficial que afirma que «la unánime aclamación que Perú ha tributado al Protocolo de Río de Janeiro constituye un auténtico plebiscito nacional» (El Protócolo de Río ante la historia, 1942). De hecho, la línea del Protocolo estaba muy por debajo de la delimitada por la Real Cédula de 1802 sobre la cual los peruanos basaban su posición jurídica, y que abarcaba toda la Amazonia al norte del Marañón, estableciendo el límite con Ecuador en el piedemonte de la Sierra. Para algunos oficiales y soldados que consideraban que hubiera sido posible apoderarse fácilmente de Guayaquil y Quito, la negociación diplomática de Prado, el alto al fuego y la posterior firma del tratado eran una traición a los caídos en la campaña25.

En esta perspectiva potencialmente desestabilizadora del Gobierno de Prado, se dio un giro de forma y de contenido a la propaganda en torno al conflicto, a partir de 1942 y con mayor énfasis en 1943, hacia la valoración del territorio amazónico que había pasado a formar parte de manera definitiva de la República del Perú.

Durante los últimos años de la Segunda Guerra Mundial, el Estado peruano afirmó su presencia en la Amazonía en el ámbito económico para aprovechar la nueva demanda de materias primas generada por la guerra, y además articular mejor la Amazonía al resto del territorio (Barclay, 1991). Este nuevo esfuerzo coincidió con actividades militares renovadas en el Nororiente (Restrepo, 1993: 158; Zanabria Zamudio, 1969: 164-199) y la construcción de caminos postergada durante mucho tiempo por los gobiernos de Óscar Benavides (1933-1939) y Manuel Prado que cambiarían profundamente las estructuras económicas de la Amazonía peruana en los años siguientes (Santos-Granero \& Barclay, 2002: 274-279; Martínez Riaza, 1998b; Walker, 1987)26.

El imaginario amazónico, construido a lo largo de la historia colonial y republicana, había penetrado la idea nacional, como lo mostraron las reacciones al conflicto de Leticia a partir de 1933 (García Jordán, 2003: 439). El conflicto de 1941 difundió por lo tanto numerosas representaciones del Oriente, mezcladas con contenidos bélicos a una escala nunca antes alcanzada.

\section{1. La exposición amazónica de 1943}

Por su amplitud y sus características, la exposición amazónica constituye la expresión más impactante de la propaganda amazónica del Gobierno de Prado.

25 Es lo que cuenta sobre el tema la tradición oral recopilada en los libros de historia. Además, ha sido confirmado por entrevistas que realizamos con excombatientes en 2015-2016.

26 Walker afirma al respecto que «la necesidad de explorar, construir redes de transporte, y poblar los vastos territorios de la selva peruana, debido a la amenaza de intrusiones extranjeras, pasó a ser parte de la conciencia nacional en el siglo diecinueve, algo que persistiría a lo largo del siglo Veinte» (Walker, 1987: 66-67). 
Esta exposición fue parte de la celebración de los 400 años del descubrimiento del río Amazonas. El asunto había ocupado un lugar muy secundario hasta que el decreto presidencial del 31 de mayo de 1941 —que oficializara este año como el de la conmemoración del cuarto centenario de la muerte del conquistador Francisco Pizarro - anunciara en uno de sus últimos artículos que se celebraría también al año siguiente el IV centenario del descubrimiento del Amazonas. La concomitancia cronológica con las grandes marchas patrióticas contra Ecuador no puede sino indicar una relación con el conflicto. A partir de 1940, Ecuador desarrolló un discurso oficial a través del Instituto Ecuatoriano de Estudios Amazónicos, bajo la conducción de Raúl Reyes y Reyes, el cual fomentó igualmente publicaciones y eventos para reclamar el descubrimiento del gran río. El año 1942 fue así dedicado por el Gobierno peruano a reivindicar no solo el legado hispanista sino sobre todo el carácter peruano del rey de los ríos, y por ende la peruanidad de la Amazonía. Todo ello contradecía la visión ecuatoriana que enfatizaba que las expediciones habían salido de Quito y que, por lo tanto, el Amazonas era ecuatoriano. En una carta de diciembre de 1941, el canciller peruano Alfredo Solf y Muro expresó muy claramente que las manifestaciones de reivindicación patriótica de la Amazonía debían ser extendidas a todo el país y llamaba a embanderar los pueblos y ciudades y organizar festejos populares27. Este contexto fue propicio a la eclosión en Perú de los temas amazónicos en las artes y la literatura (Herrera, 2018).

La exposición no era la primera de este tipo en el país. En los años anteriores, varias fueron organizadas por grupos católicos, pero sin alcanzar la misma escala que la de 194328. La práctica de las grandes exposiciones, nacionales o internacionales, que pretendían demostrar los avances de la civilización y del progreso, se había popularizado a mediados del siglo XIX en Europa. Estudios históricos sobre tal tipo de eventos han sido desarrollados ampliamente en Gran Bretaña y Francia en los treinta últimos años y están atravesados por debates sobre el impacto de la cultura visual que promovieron las exposiciones para determinar en qué medida han contribuido a forjar una cultura colonial29. En el caso peruano como en los casos europeos, se debe subrayar que estas exposiciones «constituyen precisamente herramientas eficaces de dominación política y de subyugación de individuos, grupos e instituciones potencialmente resistentes o autónomos, como la Iglesia católica o el ejército» (Vargaftig, 2016: 3).

Los discursos de inauguración de la exposición amazónica del 1 ro de junio de 1943 fueron ampliamente reproducidos en los periódicos y revistas de la capital, y

27 Alfredo Solf y Muro, ministro en el despacho de Relaciones Exteriores, al Señor Ministro de Estado en el Despacho de Gobierno y Policía, 23 de diciembre de 1941, AGN-Perú, Sección Republicana, MI 416.

28 Encontramos varios ejemplos de estas exposiciones en La Serna \& Chaumeil (2016).

29 En Gran Bretaña, el debate ha contrapuesto principalmente a John MacKenzie quien subraya el gran impacto de la «cultura imperial» y John Porter quien lo minimiza con un acercamiento más social que cultural. En Francia, el debate se ha focalizado en torno al grupo de investigación ACHAC y la noción de «zoológico humano» (Vargaftig, 2016: 14-15). 
difundidos por la radio pública 30 . Raúl Porras Barrenechea, historiador y destacado intelectual, quien había propuesto la exposición, fue explícito en relacionarla con el diferendo limítrofe con Ecuador. El historiador se posicionaba además como heredero intelectual de la generación de 1900 que vio en la Amazonía una «nueva frontera» turneriana, capaz de modernizar y dinamizar un país estancado (Walker, 1987: 80-82). Por su parte el canciller Solf y Muro anotó en esa ocasión que la exposición dejaba establecida «la posición de Perú como país amazónico» mediante los «esfuerzos de orden científico y técnico». Dentro del pabellón histórico el público podía admirar la obra diplomática de Manuel Prado en un panel que ensalzaba los esfuerzos del Presidente y de sus predecesores para asegurar el dominio peruano de la Amazonía, y la feliz conclusión alcanzada con la firma del Protocolo de Río (fig. 6). La muestra fue organizada con el auspicio del Ministerio de Relaciones Exteriores, lo que explica que los asistentes en la inauguración fueran ministros y embajadores.

El contenido de la exposición proponía así

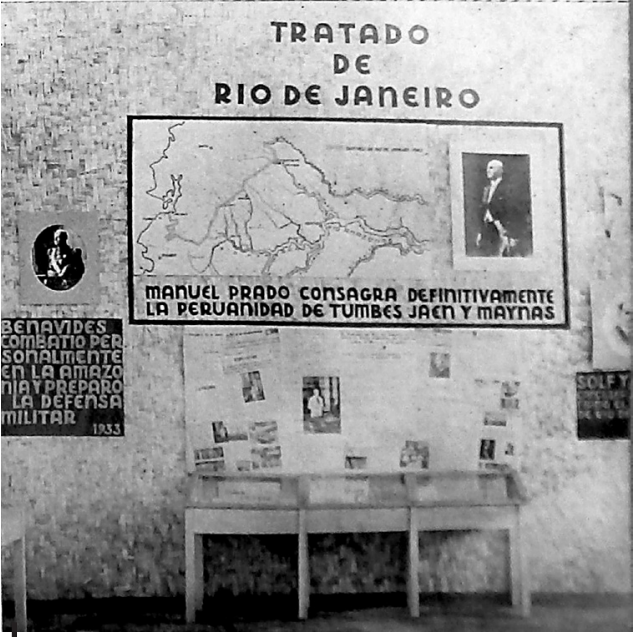

Figura 6 - El pabellón histórico insiste en el alcance de la reciente victoria para la peruanización de la Amazonía

(C) Turismo: Revista de viajes, artes, letras y actualidad, julio de 1943. Colección particular mismo una visión histórica y programática de la Amazonía considerada definitivamente peruana. Ubicada en el entonces Bosque San Felipe31, la exposición contaba con un parque de animales vivos y seis pabellones construidos para tal ocasión: misiones, historia, fuerzas armadas, industria, historia natural y un pabellón de bellas artes que albergaba frescos y obras de artistas producidos para un concurso. La muestra brindaba una visión general del imaginario amazónico que enfatizaba el clásico esfuerzo «civilizatorio» de Perú, la conversión de los indígenas al catolicismo (García Jordán, 1995 y fig. 7), la dimensión productiva y potencialmente exportadora de una selva rica y poco explotada, y por fin la visión romántica y artística de una selva misteriosa.

Esta triple visión de la Amazonía no estaba muy alejada de la que prevalecía en el siglo XIX, pero en esta ocasión el mensaje estaba destinado a llegar a un público mucho más amplio. Solamente en el mes de junio de 1943 se registraron más de 100000 visitas (Turismo, 1943).

Mucho más difícil resulta saber cómo los espectadores percibieron el mensaje, aunque los editoriales de la prensa dan indicaciones sobre ello. La Prensa resumió

30 Los discursos de Raúl Porras Barrenechea, Alfredo Solf y Muro y Ernesto Montagne fueron íntegra o parcialmente reproducidos en El Comercio, La Crónica, La Prensa, Turismo, El Mercurio Peruano, así como en la compilación posterior de Porras Barrenechea (1961).

31 Altura de la cuadra 14 de la avenida Salaverry. Hoy en día el Parque de los Próceres ocupa una parte de este espacio. 


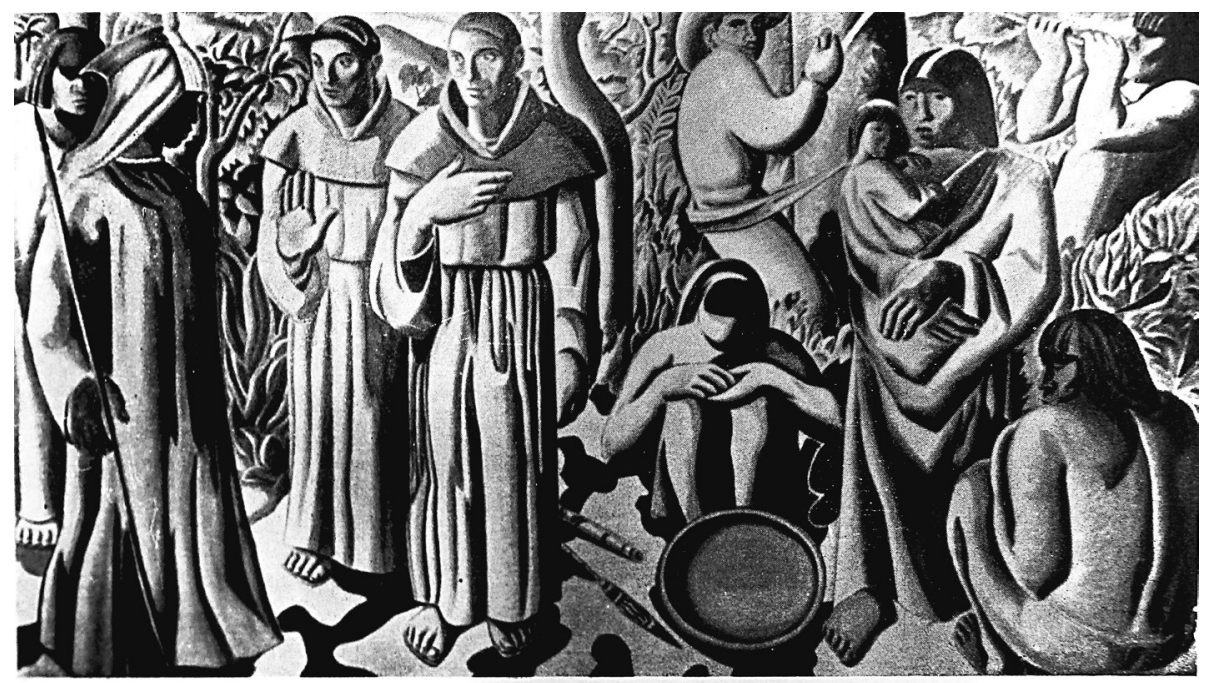

ITISSCO DI: CARLOS QLISPEZ ASIN EN EL PABELLON DE BELLAS ARTES

Figura 7 - Fresco de Carlos Quispez Asín (detalle), en la fachada del pabellón de Bellas Artes (C) El Mercurio peruano, junio de 1943

tanto el contenido del discurso civilizador como el alcance geopolítico del arreglo de Río de Janeiro. Por su parte, La Crónica enfatizó específicamente la labor de las misiones, que consistía en «atraer al terrígena [sic] y hacerlo un factor de utilidad social con los atributos del ser racional y libre», y cuando el proceso esté terminado, «se habrá coronado definitivamente aspiraciones que tienen como meta la integral rendición de aquellos grupos humanos dignos de una vida mejor como la que presiden la existencia del ciudadano y por lo mismo que ellos son tan peruanos como nosotros»32. El Comercio fue el más lírico y el más explícito, subrayando el aspecto ideológico de la exposición al declarar que «no nos interesa como a ninguno de los que la visiten, si la exposición está científicamente organizada. Eso queda para la permanencia de los Museos (...) Nos va a dejar, tal vez sin que lo sospechemos, una huella sutil y penetrante: la de llevarnos en el recuerdo, cuatro siglos de historia y de paisaje y de pujante peruanidad»33.

Sería demasiado atrevido interpretar estos editoriales como la fiel voz de toda la población. Sin embargo, es muy posible que parte del mensaje de la exposición, tuviera un fuerte impacto sobre el público y la visión de la Amazonía en Perú en los años siguientes. En este bosque de la avenida Salaverry se contribuyó a forjar la visión de la Amazonía peruana que tenemos hoy en día, además de aportar una nota positiva a una guerra que había mandado jóvenes a la muerte.

\footnotetext{
32 «La obra de las Misiones». La Crónica, 2 de junio 1943.

33 M.S.S, «Paseando la Exposición Amazónica». El Comercio, 2 de junio 1943.
} 


\section{2. Un Presidente en la Selva}

Aprovechando el entusiasmo por la Amazonía creado con la exposición, Prado se fue de gira al Oriente, entre el 2 y el 28 de setiembre de 1943. No era la primera vez que Prado viajaba por el país, ya que durante su mandato visitó todos los departamentos de Perú. No obstante, la gira por el Oriente tenía un tinte particular debido a los acontecimientos del conflicto y porque las visitas de jefes de Estado a esta parte de la República habían sido escasas hasta la fecha. El viaje servía también para inaugurar la reciente carretera que permitía llegar a Pucallpa desde Lima ${ }^{34}$. Después de ello Prado visitó Iquitos «en medio del más grande y delirante entusiasmo, como jamás se ha visto en la historia de la capital loretana»35. El Presidente incluso visitó las guarniciones selváticas de Pijuayal cerca de Colombia, y de Pantoja, en la frontera con Ecuador, vestido de su uniforme de teniente de reserva del ejército (fig. 8). De regreso, pasó por Moyobamba, celebrando el IV centenario de su fundación, visitó Chachapoyas y regresó por la costa a Lima.

En la capital, las asociaciones representativas de los departamentos orientales de Loreto, San Martín y Amazonas para honorar la gira del Presidente organizaron una «fiesta de la solidaridad amazónica» en medio de los pabellones de la exposición amazónica que todavía no cerraba. En ese contexto el presidente del Instituto Cultural San Martín, Miguel Cavero Egúsquiza, subrayó «el viraje de la acción estatal hacia el aprovechamiento de las riquezas amazónicas, que se inicia bajo [el] mandato [de Prado]». Por su parte el Presidente, seguido de un coro de niños cantando el «Himno al Oriente», destacó el desempeño de su Gobierno en la Amazonía en los ámbitos de «la vialidad, saneamiento, colonización, industrias y de su seguridad militar, así como desde el punto de vista de su moral, en la cual se destaca, como valor dominante, el amor a la Patria, antes con cierto acento de nostalgia y hoy con ardoroso optimismo». Recordó que en su viaje había sido «recibido con júbilo indescriptible» y anunció que para Perú, había «culminado su proceso formativo al conjugar el humus de la historia con el humus de la selva en la hora marcada por el destino para la total integración de las tres regiones de sus territorios y de los tres grandes matices de su fisonomía espiritual»36.

Con ocasión de la gira y de la fiesta de bienvenida en Lima se empezó a publicar el periódico Maynas, emanación de los intereses nororientales presentes en la capital peruana. Se publicó durante varios años, y en su primera edición incluía numerosos saludos al Presidente por parte de todos los sectores de la sociedad nororiental por su labor internacional y su reciente gira37.

${ }^{34}$ Sobre los debates anteriores a la construcción de la carretera, véase Martínez Riaza (1998b: 119124).

35 Maynas, Publicación informativa y literaria, Lima, n. ำ octubre de 1943.

36 Maynas, Publicación informativa y literaria, Lima, n. ${ }^{\circ}$ 1, octubre de 1943.

37 Los saludos al mandatario estaban firmados por el Vicariato Apostólico de San León del Amazonas, un sinfín de pequeños comerciantes de Iquitos (zapateros, restaurantes, panaderías, tintorerías), los empleados de la Caja de Depósitos y Consignaciones sección Iquitos, la municipalidad de Iquitos, la 


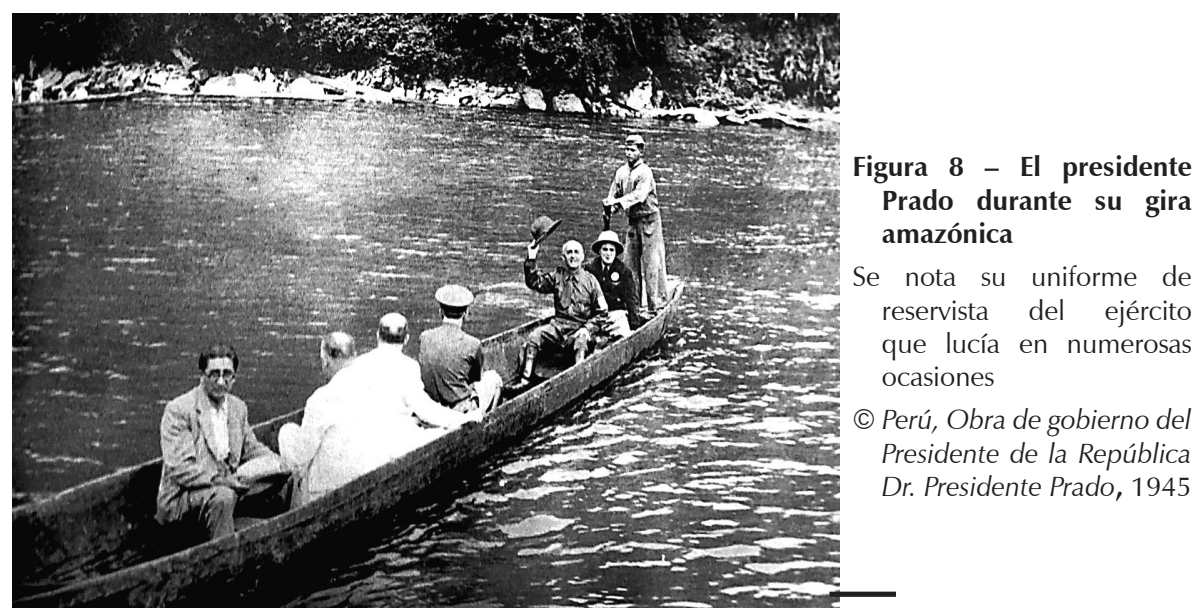

La gira conformó la apoteosis del discurso amazónico del Gobierno de Prado, mas tanto ésta como la exposición amazónica, las manifestaciones patrióticas o la película nunca estrenada tenían el inconveniente de ser temporales, y el legado de Prado, aunque declarado tantas veces transcendente para la República por sus seguidores, corría el riesgo de desaparecer. Para dejar una huella, se necesitaba entonces dejar algo concreto, construido, para siempre. En el discurso de inauguración de la conferencia amazónica, Raúl Porras Barrenechea hacía el llamado lógico de que «esta exposición que resume todas las enseñanzas y todos eso anhelos podría transformarse, bajo [la] égida [del Presidente], en un Museo amazónico». El museo nunca llegó a concretarse, pero la guerra sí tuvo su monumento.

\section{3. El monumento a los caídos}

El mensaje que quería dejar el Gobierno de Prado sería grabado para la eternidad en piedra y metal gracias a la erección de un monumento conmemorativo, para lo cual, apenas terminada la campaña de 1941, se lanzó un concurso público. El ganador fue Artemio Ocaña, un profesor de la escuela de Bellas Artes de Lima que había estudiado en Italia, y las figuras fueron fabricadas en la fundición de Bruno Campaiola gracias a una suscripción pública, «siendo esta la más grande obra de fundición ejecutada en todos los tiempos en las Américas»38. La estructura, muy imponente, fue instalada en el campo de Marte de Lima entre 1944 y 1945, donde aún se puede admirar (fig. 9).

Acción Católica diocesana de Iquitos, el Colegio Nacional de Iquitos, la Sociedad de Beneficencia Pública de lquitos, casas de importación y negociantes, etc.

38 Según la publicidad de la «Fundición Artística Estatuaria a cera perdida de Bruno Campaiola», El Comercio, 27 de julio de 1945. 


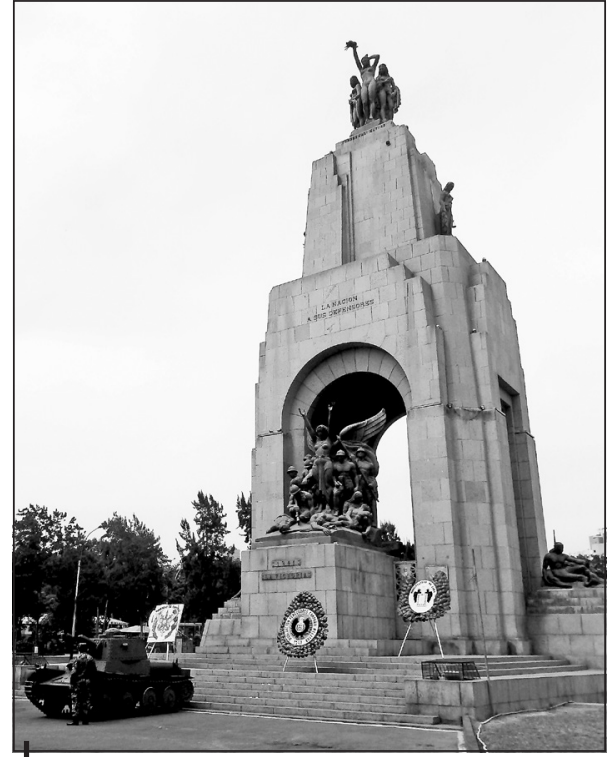

Figura 9 - El Monumento a los caídos en el campo de Marte de Lima

(C) François Bignon, julio de 2016
El monumento puede ser analizado a la luz del ornato público decimonónico que concebía los monumentos como «faros disciplinarios, intentos de formar y moldear una memoria colectiva y de crear un espacio nacional» (Majluf, 1994: 38); no solo su temática y estilo eran importantes, sino también su elaboración, ubicación e inauguración. Además, el monumento a los caídos puede ser considerado como heredero de los esfuerzos anteriores por crear las condiciones materiales de una producción nacional de este tipo de esculturas, producción que había logrado una visibilidad espectacular con el centenario de la Independencia bajo Leguía y la creación de los muchos monumentos que le fueron dedicados (Hamann, 2015).

Como resultado de un concurso público y siendo ejecutado e inaugurado por el mismo Gobierno responsable de los hechos que conmemoraba, el monumento brinda un mensaje cabal e imperecedero con relación al conflicto.

La escultura principal Ilamada «la Victoria» resalta el sacrificio de los soldados y las necesarias pérdidas de las familias para triunfar en el campo de batalla, mientras que dos estatuas alegóricas de la «Justicia» y del «Derecho» recuerdan que el Gobierno siempre afirmó haber llevado este enfrentamiento en el marco de la legalidad internacional y americana, en búsqueda de la paz. La escultura de la «Solidaridad» y las cuatro puertas doradas que representan a varios sectores de la población y de las Fuerzas Armadas, reafirman la cohesión y unidad de todos los peruanos durante este difícil momento, y borran la posibilidad de eventuales disensiones internas entre el Gobierno y los militares. En la cima del monumento las alegorías femeninas de las tres provincias ahora definitivamente peruanas - Tumbes, Jaén y Maynas - coronan estos esfuerzos y recuerdan el mensaje tempranamente defendido por Prado de la sacralidad del territorio nacional, a través de la repetición litúrgica de los topónimos, tal como había ocurrido con pancartas gigantes en las marchas patrióticas. Finalmente en los flancos del monumento se colocaron dos alegorías potentes de los grandes ríos protagonistas del encuentro armado: el Amazonas y el Marañón, representados por dos personajes amazónicos identificados por sus plumas en la cabeza y rodeados de los animales selváticos sinónimos de fuerza, peligro o exotismo: la serpiente, el jaguar, el lagarto y el mono (fig. 10). Estos animales trasmiten el mensaje de que la fuerza indomable de la selva, sus hombres y su fauna están al servicio de la nación y atados a la República para siempre gracias al sacrificio de los combatientes caídos. Llama la atención la presencia de estas alegorías selváticas, pues son probablemente las primeras de este tipo en Lima. Las vivas reacciones a una escultura remitiendo al 
pasado indígena de Perú solo unos cuantos años atrás (Ramón, 2013) nos permiten aquilatar el grado de aceptación del motivo amazónico en las artes de la época, sobre todo cuando se considera que el autor de la escultura no se ubicaba para nada en el grupo de los indigenistas (Contreras \& Cueto, eds, 2015: 280). El monumento destaca por su cohesión y su capacidad de sintetizar los mensajes del Gobierno, de justificar las acciones pasadas y de enfatizar los resultados alcanzados a través del conflicto, culminando un proceso de creación de discurso para las masas. La fecha oficial de inauguración del monumento fue el 26 de julio de 1945, en vísperas del aniversario patrio. La ceremonia tuvo que ser muy discreta porque casi no se encuentra huella de

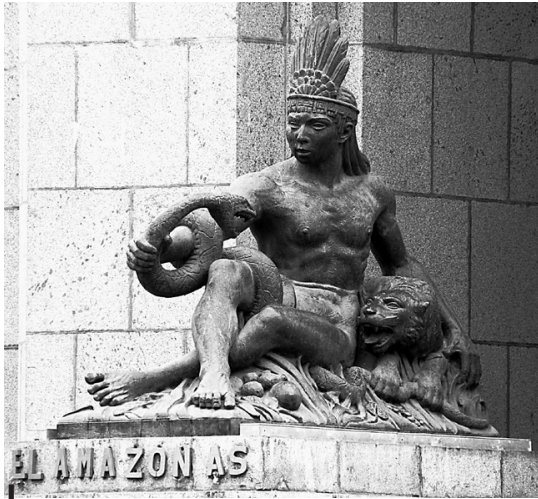

Figura 10 - El Amazonas, detalle del monumento a los caídos de 1941 (C) François Bignon, 2015 ella en los periódicos de la capital ${ }^{39}$. Esta discreción contrastaba con el entusiasmo de la suscripción popular y las portadas de las revistas sobre la obra en proceso de construcción40. ¿Cómo explicar tal silencio? Tal vez la erección progresiva del monumento había quitado algo de su novedad, pero no puede explicar un silencio total. La razón se podría encontrar más bien en el cambio de panorama político.

En efecto, dos días después de la fecha de inauguración se llevaba a cabo la transmisión de mando entre el presidente saliente y el nuevo mandatario peruano, José Luis Bustamante y Rivero. El nuevo presidente quien había asentado su carrera en las embajadas en Bolivia y Uruguay, tenía poco que ver con el conflicto de 1941. El conservador demócrata había derrotado en las elecciones nada menos que al «vencedor de Zarumilla», el general Ureta, quien se convertiría el año siguiente en Mariscal de Perú. La tremenda victoria de Bustamante $(67 \%$ contra 33\%) fue el resultado de una ola de victorias de la democracia en todo el continente después de la Segunda Guerra Mundial (Dabène, 2011: 94). Ureta, con todo su prestigio militar ganado contra Ecuador, y respaldado por el propio presidente Prado, beneficiario de la propaganda bélica de los últimos años, no pudo nada contra un casi desconocido apoyado por Oscar R. Benavides y el APRA. El clima político había cambiado y los artífices del enfrentamiento de 1941 no pudieron cosechar en los comicios la victoria de las armas.

\footnotetext{
39 Aparte del aviso publicitario de la fundición en El Comercio, no se encuentra ninguna información en las semanas inmediatamente anteriores y posteriores a la fecha indicada.

40 Véase la portada de Turismo: Revista de viajes, artes, letras y actualidad, 1944.
} 


\section{CONCLUSIÓN}

El resultado electoral muy claro a favor del candidato ajeno a la guerra nos obliga a revisar el sentido del entusiasmo patriótico en todas estas manifestaciones, editoriales, películas, exposiciones y monumentos, y relativizar el impacto que tuvieron.

No cabe duda de que hubo una política propagandística directa o indirectamente orquestada por el Gobierno de Manuel Prado a través de varios canales, pues la coherencia del mensaje se repite y se refuerza por las referencias entre las obras. La película, por ejemplo, al registrar el homenaje en el Estadio Nacional del Perú, constituye una puesta en escena de otra puesta en escena. No siempre queda claro de quién son las iniciativas de los eventos propagandísticos, pero la coherencia del mensaje nos lleva a pensar que iniciativas gubernamentales, locales y privadas, coincidieron en un fervor patriótico compartido en el país.

Sin alterar fundamentalmente la coherencia del discurso, el contenido del mismo tuvo que cambiar para adaptarse a las evoluciones de la opinión pública. Mientras que, en un principio, se limitaba a afirmar la sacralidad del territorio y el respaldo consensual al presidente Prado, se fue enfocando después en la figura del caído, para posteriormente volcarse totalmente a la admiración por el legado amazónico. La insistencia en los caídos, además de encajar con la tradición latinoamericana de los héroes ${ }^{41}$, podía contrarrestar las críticas a una propaganda exclusivamente centrada en la familia Prado. El giro amazónico dio un tinte positivo y épico a un evento bélico por naturaleza dramático, logrando acallar las críticas acerca de un arreglo diplomático potencialmente desfavorable para Perú.

A pesar de estos cambios, cabe destacar que la temática de la paz estuvo presente con fuerza desde un principio. No solo se puede analizar este hecho paradójico por la práctica diplomática de siempre decir lo contrario de lo que uno realmente hace, sino como un verdadero ideal compartido por la mayoría de las cancillerías americanas a raíz de varias reuniones panamericanas y de diversos proyectos ambiciosos de paz total y definitiva en el hemisferio, cuyo mejor ejemplo es el Tratado antibélico (Saavedra Lamas, 1932) del canciller argentino Saavedra Lamas.

Además del contenido, los canales de transmisión del mensaje también evolucionaron a medida que los eventos transcurrían, entre 1940 y 1945. Así, los canales fueron concebidos cada vez más para la permanencia. De las manifestaciones callejeras a la película, de la exposición temporal a la eternidad de la piedra y del metal, el discurso intentó paulatinamente proyectarse en el tiempo para dejar una huella profunda. Se puede también interpretar esta tendencia como el propósito de controlar las reacciones espontáneas de la calle para no perjudicar la diplomacia peruana. El monumento, a diferencia del manifestante, no es imprevisible.

41 La ausencia total, en los mensajes estudiados, de la figura de José A. Quiñones, héroe máximo de esta guerra en el Perú, supone la construcción posterior de esta figura y requiere más investigación. 
¿Ha logrado su propósito esta propaganda? En cuanto a limpiar el nombre de los Prado, el efecto fue ambiguo. Manuel Prado consiguió terminar su mandato, declarar a su padre prócer de la nación y fue reelecto en 1956. Sin embargo, su derrocamiento por los militares en 1962 y las polémicas del año 2015 en torno al «Expediente Prado» (García Belaúnde, 2014) muestran que la vieja acusación de traición no ha desaparecido del todo 42 .

En cuanto al entusiasmo por la Amazonía, hay que subrayar que este «redescubrimiento de la Amazonía» (al decir de Raúl Porras) coincide con un cambio de era, que vería en la segunda mitad del siglo XX la explotación más sistemática y a gran escala del Nororiente peruano. Asimismo, varios de los temas amazónicos desarrollados en el fervor de la guerra se encuentran en la obra del presidente Belaúnde (Belaúnde Terry, 1994). No obstante, resulta difícil medir el impacto cultural de esta propaganda en el tiempo. El gran olvido en el cual se encuentra el conflicto de 1941 para las nuevas generaciones nos lleva más bien a concluir que el entusiasmo patriótico fue verdadero en el país, pero utilizado con exceso por el Gobierno y muy limitado en el tiempo.

\section{Referencias citadas}

\section{Fuentes primarias}

AGN-Perú, Sección Republicana, MI 144, 1941 - Alejandro F. Barrios, Secretario del Presidente de la República, al Director de Gobierno, of. n. ${ }^{\circ} 1561,14$ de marzo de 1941.

AGN-Perú, Sección Republicana, MI 415, 1941 - Decreto Supremo del 17 de mayo de 1941, citado en A. de la Fuente, Ministro de Guerra, al Ministro de Estado en el Despacho de Gobierno y Policía, n. ${ }^{\circ}$ 165A/I.G, 20 de mayo de 1941.

AGN-Perú, Sección Republicana, MI 416, 1941 - Alfredo Solf y Muro, ministro de Relaciones exteriores, al Ministro de Estado en el Despacho de Gobierno y Policía, Lima, n. ${ }^{\circ} 2-0 / 119,16$ de setiembre de 1941.

AGN-Perú, sección republicana, MI 418, 1941 - Secretaría de la Cámara de Diputados al Señor Ministro de Estado en el Despacho de Gobierno y Policía, 14 de agosto de 1941.

AGN-Perú, Sección Republicana, MI 416, 1941 - Alfredo Solf y Muro, ministro en el despacho de Relaciones Exteriores, al Señor Ministro de Estado en el Despacho de Gobierno y Policía, n. ${ }^{\circ}$ 2-0/164, 23 de diciembre de 1941.

\section{Fuentes secundarias}

ALMEIDA, F. d', 2013 - Une histoire mondiale de la propagande : De 1900 à nos jours, 194 pp.; París: Éditions de la Martinière.

42 La ley n. 10023 del 24 de noviembre de 1944 declara a Mariano Ignacio Prado «prócer de la nación». Sin embargo en 2014, el libro de un congresista acusándolo de haber traicionado a la patria obligó a varias personalidades políticas y de la familia Prado a opinar sobre el tema (García Belaunde, 2014). 
BARCLAY, F., 1991 - Protagonismo del Estado en el proceso de incorporación de la Amazonía. In: Amazonía, 1940-1990: el extravío de una ilusión (F. Barclay, F. Santos, M. Rodríguez \& M. Varcárcel, eds.): 43-100; Roma, Lima: Terra Nuova, PUCP-CISEPA.

BEDOYA, R., 1995 - 100 años de cine en el Perú. Una historia crítica, 459 pp.; Lima: Universidad de Lima, Fondo de Desarrollo Editorial.

BEDOYA, R., 1997 - Un cine reencontrado: diccionario ilustrado de las películas peruanas, 343 pp.; Lima: Universidad de Lima, Fondo de Desarrollo Editorial.

BEDOYA, R., 2014 - Más sobre Alerta en la frontera | Páginas del diario de Satán. Recuperado a partir de http://www.paginasdeldiariodesatan.com/pdds/?p=646 Consultado el 27 de febrero de 2017.

BELAÚNDE TERRY, F., 1994 - La conquista del Perú por los peruanos, 352 pp.; Lima: Editorial «Minerva».

BIGNON, F., 2015 - Jeux d'échelles dans les Andes : le conflit péruano-équatorien de 1941 1942 et la Seconde Guerre mondiale. Relations internationales, n. ${ }^{\circ} 162$ (3): 63-78.

BYTWERK, R. L., 2004 - Bending Spines: The Propagandas of Nazi Germany and the German Democratic Republic, 228 pp.; East Lansing, Mich: Michigan State University Press.

CAMACHO ARANGO, C., 2016 - El conflicto de Leticia (1932-1933) y los ejércitos de Perú y Colombia, 515 pp.; Bogotá: Universidad Externado de Colombia-CEHIS.

CONTRERAS, C. \& CUETO, M. (eds.), 2015 - América Latina en la historia contemporánea, tomo 4: Perú. Mirando hacia dentro, 312 pp.; Madrid: Taurus, Fundación MAPFRE.

DABÈNE, O., 2011 - L'Amérique latine à l'époque contemporaine, 271 pp.; París: Armand Colin. Séptima edición.

DENEGRI LUNA, F., 1996 - Perú y Ecuador: apuntes para la historia de una frontera, 378 pp.; Lima: Bolsa de Valores de Lima.

EL COMERCIO, 1943 - Paseando la Exposición Amazónica, 2 de junio de 1943.

EL COMERCIO, 1945 - Fundición Artística Estatuaria a cera perdida de Bruno Campaiola, 27 de julio de 1945.

EL MERCURIO PERUANO, 1943 - Junio de 1943, Año XVIII, vol. XXV, n. ${ }^{\circ}$ 195. Revista mensual de ciencias sociales y letras.

EL PROTÓCOLO DE RÍO ANTE LA HISTORIA, 1942 - Lima.

ELLUL, J., 1967 - Histoire de la propagande, 136 pp.; París: Presses universitaires de France (PUF).

FACON, P., 2013 - 1914-1918 la guerre des affiches. La grande guerre racontée par les images de propagande, 192 pp.; Grenoble: Éditions ATLAS.

FRANK, R., 2012 - Pour l'histoire des relations internationales, 776 pp.; París: Presse Universitaire de France (PUF).

GÁNDARA ENRÍQUEZ, M., 2000 - El Ecuador del año 1941 y el Protocolo de Rio: Antecedentes, hechos subsiguientes: Arroyo y su tiempo, 938 pp.; Quito: Centro de Estudios Históricos del Ejército.

GARCÍA BELAÚNDE, V. A., 2014 - El expediente Prado; Lima: Universidad San Martín de Porres.

GARCÍA JORDÁN, P., 1995 - Las misiones católicas en la Amazonía peruana: ocupación del territorio y control indígena (1821-1930). In: La construcción de la Amazonía andina (siglos XIX-XX) (Pilar García Jordán, ed.): 7-106; Quito: Abya-Yala.

GARCÍA JORDÁN, P., 2003 - Cruz y arado, fusiles y discursos: la construcción de los Orientes en el Perú y Bolivia, 1820-1940; Lima: Instituto Francés de Estudios Andinos (IFEA), Instituto de Estudios Peruanos (IEP). 
Propaganda pradista: Patria, caídos y Amazonía en torno a la guerra Perú-Ecuador de 1941

HAMANN, J., 2015 - Leguía, el Centenario y sus monumentos. Lima: 1919-1930, 476 pp.; Lima: Pontificia Universidad Católica del Perú (PUCP)-Fondo Editorial.

HERRERA, M., 2018 - La construcción de la peruanidad de la Amazonía: el caso del IV Centenario del Descubrimiento del Río Amazonas de 1942. Revista del Instituto Riva-Agüero, vol. 3, n. ${ }^{\circ}$ 2: 121-169.

IBARRA, H., 1999 - La guerra de 1941 entre Ecuador y Perú: una reinterpretación, 118 pp.; Quito: Centro Andino de Acción Popular.

LA CRÓNICA, 1943 - «La obra de las Misiones», 2 de junio 1943.

LA SERNA, J. C. \& CHAUMEIL, J.-P., 2016 - El bosque ilustrado. Diccionario histórico de la fotografía amazónica peruana (1868-1950), 294 pp.; Lima: IFEA, CAAAP, EREA, PUCP.

LÓPEZ, S. \& BARRENECHEA, M., 2005 - Perú, 1930-1968: competencia y participación en el Estado oligárquico. In: Historia de las elecciones en el Perú: estudios sobre el gobierno representativo (C. Aljovín de Losada \& S. López, eds.): 109-178; Lima: IEP.

LOSSIO, J. \& CANDELA, E., 2015 - Prensa, conspiraciones y elecciones: el Perú en el ocaso del régimen oligárquico, 155 pp.; Lima: Pontificia Universidad Católica del PerúInstituto Riva-Agüero.

MAJLUF, N., 1994 - Escultura y espacio público. Lima, 1850-1879, 63 pp.; Lima: IEP.

MARTíNEZ RIAZA, A., 1998a - Estrategias de ocupación de la Amazonía. La posición española en el conflicto Perú-Ecuador (1887-1910). In: Fronteras, colonización y mano de obra indígena en la amazonía andina (siglos XIX-XX) (P. García Jordán, ed.): 241-335; Lima: Pontificia Universidad Católica del Perú, Fondo Editorial

MARTíNEZ RIAZA, A., 1998b - La incorporación de Loreto al Estado nación peruano. El discurso modernizador de la Sociedad Geográfica de Lima (1891-1919). In: La nacionalización de la Amazonía (P. García Jordán \& N. Sala i Vila, eds.): 99126; Barcelona: Universitat de Barcelona-UB-Taller de estudios e investigaciones andino-amazónicos.

MASTERSON, D. M., 2001 - Fuerza armada y sociedad en el Perú moderno: un estudio sobre relaciones civiles militares, 1930-2000, 496 pp.; Lima: Instituto de Estudios Políticos y Estratégicos.

MAYNAS, 1943 - Publicación informativa y literaria, Lima, n. 1, octubre de 1943.

OFICINA DE INFORMACIONES DEL PERÚ, 1941 - El Presidente Prado no admite discusión sobre la intangibilidad de la soberanía nacional en las provincias de Tumbes, Jaén y Mainas; Lima.

PASTOR, A., 2013 - Images de propagande 1914-1918 ou l'art de vendre la guerre, 160 pp.; París: Desinge \& Hugo \& cie.

PERÚ, obra de gobierno del Presidente de la República, Dr. Manuel Prado: 1939-1945 1945; Buenos Aires

PIZARROSO QUINTERO, A., 1990 - Historia de la propaganda, 475 pp.; Madrid: Ed. Eudema.

PIZARROSO QUINTERO, A., 1999 - La historia de la propaganda: una aproximación metodológica. Historia y Comunicación Social, 4: 145-171.

PORRAS BARRENECHEA, R., 1961 - El Perú y la Amazonia, 54 pp.; Lima: s.e.

PORTOCARRERO, F., 1995 - El imperio Prado, 1890-1970, 312 pp.; Lima: Universidad del Pacifico.

RAMÓN, G., 2013 - El inca indica Huatica: simbología pre-colonial e intervención urbana en Lima, 1920-1940. In: Lima, siglo XX. Cultura, socialización y cambio (C. Aguirre \& A. Panchifi, eds.): 21-56; Pontificia Universidad Católica del Perú-Fondo Editorial. 
RESTREPO, M., 1993 - El problema de la frontera en la construcción del espacio amazónico. In: Amazonía: escenarios y conflictos (L. Ruiz, ed.): 149-169; Quito: Centro de Investigación de los Movimientos Sociales del Ecuador (CEDIME).

Saavedra Lamas, C., 1932 - Proyecto de tratado antibélico, 31 p.; Buenos Aires: Ministerio de Relaciones exteriores y culto.

SANTOS-GRANERO, F. \& BARCLAY, F., 2002 - La frontera domesticada: historia económica y social de Loreto, 1850-2000, 566 pp.; Lima: Pontificia Universidad Católica del Perú (PUCP)-Fondo Editorial.

TOBAR DONOSO, J., 1982 - La invasión peruana y el Protocolo de Río: antecedentes y explicación histórica, 559 pp.; Quito: Banco Central del Ecuador.

TURISMO, REVISTA DE VIAJES, ARTES, LETRAS Y ACTUALIDAD, 1941 - Año VI, n. ${ }^{\circ} \mathbf{6 3}$ agosto de 1941.

TURISMO, REVISTA DE VIAJES, ARTES, LETRAS Y ACTUALIDAD, 1943 - Revista de viajes, artes, letras y actualidad, Año VIII, n. ${ }^{\circ} \mathbf{8 5}$, julio de 1943.

TURISMO, REVISTA DE VIAJES, ARTES, LETRAS Y ACTUALIDAD, 1944 - Revista de viajes, artes, letras y actualidad, Año IX, n. ${ }^{\circ} \mathbf{1 0 0}$, octubre de 1944.

VARGAFTIG, N., 2016 - Des Empires en carton. Les Expositions coloniales au Portugal et en Italie (1918-1940), 344 pp.; Madrid: Casa de Velázquez.

WALKER, C., 1987 - El uso oficial de la selva en el Perú republicano. Amazonía peruana, 4 (8): 61-89.

YEPES, E., 1998 - Tres Días de Guerra Ciento Ochenta de Negociaciones, Perú-Ecuador 1941-1942, xliii + 426 pp.; Lima: Universidad Nacional La Molina.

ZANABRIA ZAMUDIO, R., 1969 - Luchas y victorias por la definición de una frontera. La lucha en el dominio político, xi + 398 pp.; Lima: Editorial Jurídica.

ZANABRIA ZAMUDIO, R., 1996 - La campaña de 1941 (Perú-Ecuador), 548 pp.; Lima: Editora Impresora Amarilys eirl. 